\title{
Glucose Utilization by the Placenta and Fetal Tissues in Fed and Fasted Pregnant Rabbits
}

\author{
S. HAUGUEL, A. LETURQUE, M. GILBERT, ${ }^{1}$ J. KANDE, AND J. GIRARD \\ Centre de Recherche sur la Nutrition du CNRS, 92190 Meudon-Bellevue, France
}

\begin{abstract}
Glucose utilization by the placenta and individual fetal tissues was studied in vivo in conscious pregnant rabbits at 29 days of gestation. In the fed state, the rate of glucose utilization was similar in the placenta and the gravid uterus, suggesting that the rate of fetal glucose utilization was approximately $40 \mathrm{nmol} / \mathrm{min} / \mathrm{g}$. A 96-h maternal fast induced a significant decrease in glucose utilization by the myoendometrium and in the glucose utilization index by fetal liver and brown adipose tissue. No modification was observed in other fetal tissues. These results indicate that glucose utilization by the placenta and the whole fetus from 96-h fasted rabbits does not decrease despite profound changes in endocrine and metabolic maternal parameters. (Pediatr Res 23: 480-483, 1988)
\end{abstract}

\section{Abbreviations}

FFA, free fatty acids

2DG, 2-deoxyl-[1-3 H]glucose

GU, glucose uptake

$\mathrm{KB}$, ketone body

Metabolic requirements of the gravid uterus have been quantified in vivo in the cow (1) and the sheep (2) and more recently in the guinea pig (3) and the rabbit (4). The growth and oxidative metabolism of the mammalian fetus are largely dependent on the rates of fetal glucose and amino acid utilization (5). Most of these studies have been carried out using chronic vascular catheterization and measurements of overall substrate uptake by the fetus and the placenta by means of the Fick principle methodology. However, this technique does not permit determination of substrate utilization by individual tissues of the fetus in small mammalian species.

In this respect, the rabbit is of interest because: 1 ) use of the radioactive 2-deoxyglucose technique, adapted to rodents (6) can be coupled to determination of blood flow and venous-arterial blood glucose concentration difference across the uterus; 2) maternal FFA cross the placenta in this species (7) and can potentially replace glucose as fuel for fetal tissues, particularly during maternal fasting when increased amounts of FFA are transferred to the fetus (8). The aim herein was to quantify glucose utilization by individual tissues in the fetal rabbit and to determine the partition of glucose between the myoendometrium, the placenta, and the fetus in the fed and fasted state. The experiments were performed on day 29 of gestation in chronically catheterized pregnant rabbits.

Received July 13, 1987; accepted January 6, 1988

Correspondence Dr S. Hauguel, Centre de Recherche sur la Nutrition, 9 rue Jules Hetzel, 92190 Meudon, France.

'Present address Laboratoire de Physiologie du Développement, Collège de France, 11 Place Marcelin Berthelot, 75005 Paris.

\section{MATERIALS AND METHODS}

Animals. Female rabbits from the "Fauve de Bourgogne" strain were obtained from a commercial breeder and were housed in individual stainless steel cages. Mating was performed in the laboratory and the day of mating was taken as day zero of pregnancy. On day 25 of gestation pregnant rabbits were separated into two groups. The first group was fed a solid commercial rabbit diet ad libitum (caloric percentage:carbohydrate $68 \%$, protein $22 \%$, fat $10 \%$ ) (Sanders Laboratory, Paris, France) until day 29 of gestation; food intake was measured daily. The second group was fasted for $96 \mathrm{~h}$. All animals had free access to water.

Surgical procedure. Surgery was carried out on day 21 of pregnancy under ketamine hydrochloride $(35 \mathrm{mg} / \mathrm{kg}$ intramuscularly) and xylazine hydrochloride (6 $\mathrm{mg} / \mathrm{kg}$ intramuscularly) anesthesia. Under sterile conditions maternal vessels were catheterized. Polyvinyl catheters were inserted into one jugular vein to allow radioactive tracer infusions and into one femoral artery and one branch of the uterine vein for blood sampling under conscious, unrestrained conditions (4). In addition, an intracardiac catheter was advanced to the left ventricle through the right carotid artery to allow blood flow measurements (4). All catheters were tied in place and tunneled subcutaneously to exit into a plastic cap sutured into place in the interscapular region. Catheters were filled with an heparinized solution $(800 \mathrm{IU} / \mathrm{ml}$ saline) and were flushed every 3 days to keep them patent. Detailed description of the surgical procedures has been reported previously (4).

Measurements of glucose utilization by the placenta, the uterus, and fetal tissues. Experiments were carried out in vivo on day 29 of gestation in fed and 96-h fasted does. The radioactive 2deoxyglucose technique recently adapted to the rat fetus was used $(9,10)$. Glucose utilization index was determined in individual tissues after an intravenous injection of $250 \mu \mathrm{Ci} 2 \mathrm{DG}$ in the conscious pregnant rabbits. Maternal arterial blood was sampled at $1,3,5,10,15,20,40,60,80$, and 120 min after the radioactive $2 D G$ injection for the determination of radioactive 2DG and of glucose concentrations.

The ${ }^{3} \mathrm{H}-2 \mathrm{DG}-6$-phosphate which accumulates in various tissues cannot be further metabolized and represents an index of glucose used inasmuch as any molecule of glucose which enters the cell is phosphorylated before being incorporated into glycogen or metabolized through the glycolytic pathway. The accumulation of ${ }^{3} \mathrm{H}-2 \mathrm{DG}-6$-phosphate in various tissues was measured in steady state conditions for blood glucose concentration and glucose utilization rates as described in the adult rat (6).

Tissue and blood sampling. Maternal arterial blood was withdrawn from the femoral artery just before and $120 \mathrm{~min}$ after the $2 \mathrm{DG}$ injection. At $120 \mathrm{~min}$, after maternal laparotomy, fetal blood was obtained from axillary vessels under pentobarbital anesthesia (11). During fetal blood sampling, the placenta was left in situ and the maternal glycemia remained constant, indicating that fetal biochemical parameters are representative of the maternal steady state. At the end of the experiments, mothers 
were killed by an overdose of pentobarbital and two fetoplacental units adjacent to the ovaries were rapidly excised and the portion of the uterine horn surrounding one fetus and its placenta was carefully dissected out. The myoendometrium, placenta, and fetus corresponding to each fetoplacental unit were removed and weighed. Uterine, placenta, and individual fetal tissues (hindlimb muscle, diaphragm, heart, liver, brain, skin, and white and brown adipose tissue) were rapidly dissected out. These tissues have very low glucose-6-phosphatase activity at this stage of gestation $(12,13)$ and thus the hydrolysis of 2DG-6-phosphate back to 2DG was considered to be negligible. Determinations of radioactivity in blood samples and measurements of tissue ${ }^{3} \mathrm{H}-2 \mathrm{DG}-$ 6-phosphate content were performed according to the technique described previously in the rat $(6,10)$.

Determination of the lumped constant for the gravid uterus. The lumped constant that is a correction factor for the discrimination against 2-deoxyglucose in glucose transport and phosphorylation pathways was determined in vivo for one fetoplacental unit (fetus, placenta, and surrounding myoendometrium). It is represented by the difference between maternal and fetal blood radioactive $2 \mathrm{DG} /$ glucose specific activity because axillary blood of the fetus represents efferent blood from the uteroplacenta (9). A primed continuous venous infusion of 2 -deoxy- $\left[1-{ }^{14} \mathrm{C}\right]$ glucose $(0.52 \mu \mathrm{Ci} / \mathrm{min})$ in saline was performed during $60 \mathrm{~min}$ to obtain a steady blood 2DG specific activity. Blood samples were then obtained in steady state conditions (9) through the maternal femoral artery and via axillary fetal vessels. The samples were deproteinized and the supernatants were treated as described previously (6). The ratio of maternal arterial blood ${ }^{14} \mathrm{C}-2 \mathrm{DG} /$ glucose to fetal blood ${ }^{14} \mathrm{C}-2 \mathrm{DG} /$ glucose was found to be $0.81 \pm$ $0.04(n=7)$ and was not significantly altered by fasting: $0.72 \pm$ $0.04(n=6)$.

Calculation of glucose utilization index by various tissues. The glucose utilization index was expressed as ${ }^{3} \mathrm{H}-2 \mathrm{DG}-6$-phosphate content of each fetal tissue divided by the integral of the ratio of maternal arterial blood ${ }^{3} \mathrm{H}-2 \mathrm{DG}$ to glucose over a 120 -min period. In the present experiments, the lumped constant of fetal tissues was not determined and the results were expressed as glucose utilization indices rather than glucose utilization rates. For the placenta and myoendometrium, the rates of glucose utilization were calculated by dividing the glucose utilization index by the calculated lumped constant.

Measurement of total glucose uterine uptake. The GU by one fetoplacental unit was measured using the Fick pripriple methodology and calculated according to the formula: GU (nmol/ $\min / \mathrm{g})=$ venous-arterial glucose concentration difference across the uterus $(\mu \mathrm{mol} / \mathrm{ml}) \times$ uteroplacental blood flow $(\mathrm{ml} / \mathrm{min} / \mathrm{g})$.
Both variables were measured in steady state conditions in fed and fasted pregnant rabbits. Paired venous and arterial blood samples were drawn simultaneously as described previously (4). Uteroplacental blood flow was measured in conscious animals using radioactive microspheres labeled with ${ }^{113}$ Tin (NEN, Dreleich, W. Germany). Calculations of uterine blood flows were done by the reference sample method (4).

Biochemical measurements. Blood glucose concentration was determined by the glucose oxidase method (Boehringer, Meylan, France) on blood supernatant deproteinized with $\mathrm{Ba}(\mathrm{OH})_{2-}$ $\mathrm{ZnSO}_{4}$. Blood ketone body and lactate concentrations were measured on neutralized perchloric acid $(6 \%, \mathrm{w} / \mathrm{v})$ supernatants $(14,15)$. Plasma FFA concentrations were measured by an enzymatic method (NEFA C kit, Biolyon, Lyon, France) (4). Plasma insulin was determined by radioimmunoassay on aliquots of the last blood samples using rabbit insulin as standard (16).

Statistics. Results are presented as means \pm SEM. Statistical differences were evaluated using the Student's $t$ test.

\section{RESULTS}

Metabolic and hormonal changes induced by maternal fasting. Maternal, fetal, uteroplacental weights, and blood flow remained unchanged after a maternal fast of $96 \mathrm{~h}$ (Table 1). Changes in fetal and maternal endocrine and metabolic parameters are shown in Table 2 . Maternal fasting for $96 \mathrm{~h}$ was associated with a $20 \%$ decrease in blood glucose, a 5-fold increase in blood KB concentration and a 2 -fold increase in plasma FFA concentration. By contrast, the changes induced by fasting were smaller in the fetuses than in the mothers. Although blood glucose was decreased and ketonemia raised, the differences observed did not reach statistical significance. Fetal plasma FFA concentration was increased 3-fold $(p<0.01)$. The permeability of the rabbit placenta to glucose, FFA, and KB was estimated by calculating maternofetal substrate concentration gradients (Fig. 1). Whereas maternofetal gradients for glucose and FFA were not significantly lowered during maternal fasting, an important decrease of maternofetal $\mathrm{KB}$ gradient was observed, suggesting a limited transfer of $\mathrm{KB}$ from maternal to fetal circulation. Both fetal and maternal plasma insulin concentrations were markedly decreased by maternal fasting (Table 2).

Glucose utilization by the fetoplacental unit. The rates of glucose utilization by the placenta, the myoendometrium, and the fetoplacental unit (myoendometrium + placenta + fetus) are shown in Figure 2. Results are expressed as rates of glucose utilization inasmuch as values obtained for the myoendome-

Table 1. Fetoplacental parameters in 29-day pregnant rabbits (mean \pm SE)

\begin{tabular}{lcccccc}
\hline & Maternal wt & Mean fetal & Mean placental \\
wt $(\mathrm{g})$ & $\begin{array}{c}\text { Mean wt of one } \\
\text { fetoplacental } \\
\text { unit }(\mathrm{g})\end{array}$ & $\begin{array}{c}\text { Mean placental } \\
\text { blood flow } \\
(\mathrm{ml} / \mathrm{min})\end{array}$ & $\begin{array}{c}\text { Mean uteroplacental } \\
\text { blood flow (ml/min) }\end{array}$ \\
\hline Fed $(n=7)$ & $3800 \pm 200$ & $39 \pm 3$ & $6.3 \pm 0.7$ & $58 \pm 1$ & $3.28 \pm 0.18$ & $4.45 \pm 0.32$ \\
96 -h fasted $(n=7)$ & $3600 \pm 100$ & $34 \pm 3$ & $5.8 \pm 0.7$ & $57 \pm 4$ & $3.07 \pm 0.39$ & $4.20 \pm 0.43$ \\
\hline
\end{tabular}

Table 2. Blood substrates (mmol/liter) and plasma insulin $(\mu \mathrm{U} / \mathrm{ml})$ concentrations in 29-day fed or fasted pregnant rabbits and their fetuses (mean $\pm S E$ )

\begin{tabular}{|c|c|c|c|c|c|c|}
\hline & Glucose & 3-Hydroxybutyrate & Acetoacetate & Lactate & FFA & Insulin \\
\hline \multicolumn{7}{|l|}{ Mothers } \\
\hline Fed $(n=7)$ & $5.43 \pm 0.17$ & $0.21 \pm 0.05$ & $0.17 \pm 0.06$ & $1.40 \pm 0.09$ & $0.79 \pm 0.17$ & $48 \pm 8$ \\
\hline $96-\mathrm{h}$ fasted $(n=7)$ & $4.44 \pm 0.22^{*}$ & $1.2 \pm 0.4^{*}$ & $0.87 \pm 0.10^{*}$ & $1.65 \pm 0.27(\mathrm{NS})$ & $1.62 \pm 0.20 \dagger$ & $2 \pm 1^{*}$ \\
\hline \multicolumn{7}{|l|}{ Fetuses } \\
\hline Fed $(n=11)$ & $4.21 \pm 0.22$ & $0.16 \pm 0.08$ & $0.19 \pm 0.06$ & $8.0 \pm 1.0$ & $0.06 \pm 0.01$ & $115 \pm 19$ \\
\hline 96-h fasted $(n=12)$ & $3.66 \pm 0.17(\mathrm{NS})$ & $0.35 \pm 0.18(\mathrm{NS})$ & $0.30 \pm 0.07(\mathrm{NS})$ & $6.5 \pm 1.1(\mathrm{NS})$ & $0.19 \pm 0.04 \dagger$ & $21 \pm 4^{*}$ \\
\hline
\end{tabular}

$p$ values refer to differences between fasted and fed state. ${ }^{*} p<0.001, \dagger p<0.01$. 
( mmoles/l)

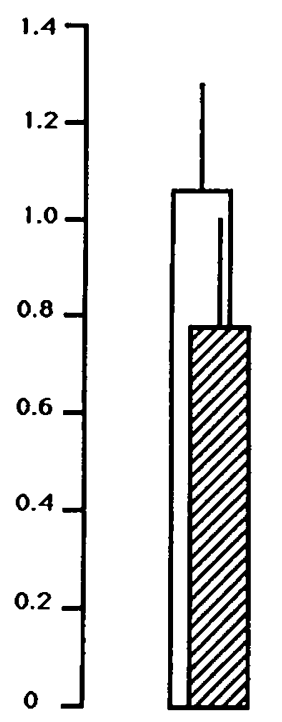

GLUCOSE

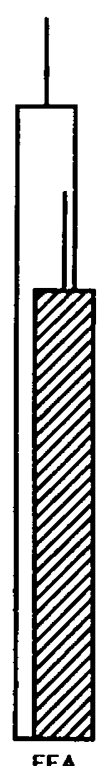

FFA
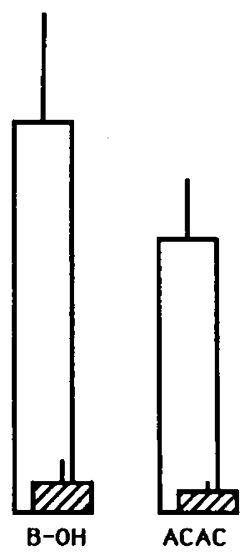

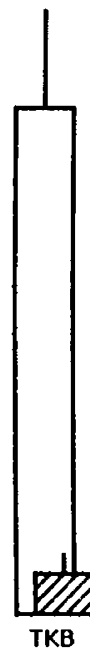

Fig. 1. Maternofetal substrate concentration gradients in fed $\square$ and fasted pregnant rabbits. $B-O H, 3$ hydroxybutyrate; $A C A C$, acetoacetate; $\mathrm{TKB}$, total KB.
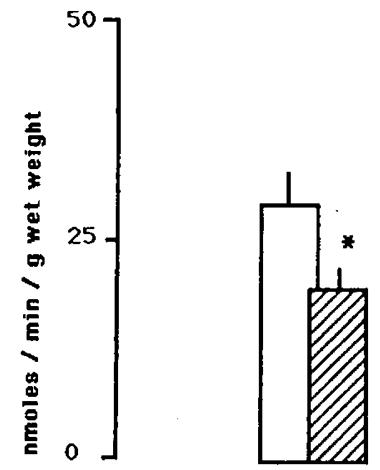

MYOMETRIUM

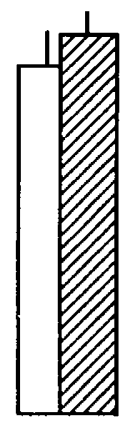

PLACENTA

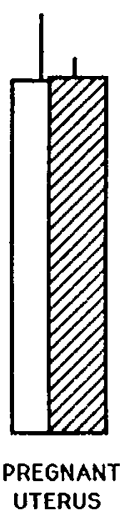

Fig. 2. Glucose utilization in myometrium (uterine muscle), placenta, and one fetoplacental unit (fetus + placenta + myometrium) in fed $\square$ and 96-h fasted ש pregnant rabbits. ${ }^{*} p<0.01$.

trium and the placenta have been corrected by the mean lumped constant (0.76) of the gravid uterus (see "Materials and methods"). In the fed state, placental glucose utilization measured by the radioactive $2 D G$ method $(40.5 \pm 3.9 \mathrm{nmol} / \mathrm{min} / \mathrm{g})$ is in the range of values obtained by the Fick method for the fetoplacental unit $(41.1 \pm 7.2 \mathrm{nmol} / \mathrm{min} / \mathrm{g})$. Glucose utilization by the myoendometrium $(29.9 \pm 3.9 \mathrm{nmol} / \mathrm{min} / \mathrm{g})$ was not statistically different $(p>0.05)$ from placental glucose utilization $(40.5 \pm 3.9$ $\mathrm{nmol} / \mathrm{min} / \mathrm{g}$ ). After maternal fasting, glucose utilization was significantly decreased $(-33 \%)$ in the myoendometrium $(p<$ 0.01 ) but remained unchanged in the placenta and the fetoplacental unit.

Glucose utilization index in individual fetal tissues. The glucose utilization index of liver and brown adipose tissue (Fig. 3) were significantly decreased in fetuses from fasted mothers (11 \pm 0.5 versus $7.2 \pm 0.5$ and $27 \pm 2.2$ versus $7.8 \pm 1.2 \mathrm{nmol} / \mathrm{min} / \mathrm{g}$, respectively). By contrast, the glucose utilization index of fetal muscles (hindlimb, diaphragm, heart), white adipose tissue, skin, and brain was not modified by maternal fasting.

\section{DISCUSSION}

The fetoplacental unit is a complex structure composed of the fetus and the placenta attached to the surrounding myoendo-

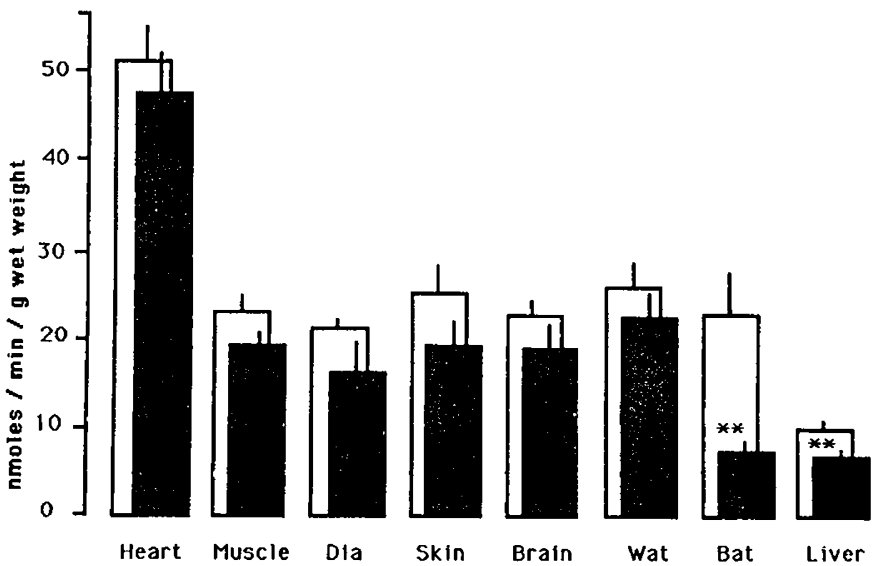

Fig. 3. Glucose utilization index of individual tissues in fetuses from fed $\square$ and 96-h fasted mothers. Dia, diaphragm; Wat, perirenal white adipose tissue; Bat, interscapular brown adipose tissue.

metrium. In a number of mammalian species the gravid uterus is composed of only one fetus and one placenta, and therefore quantitative information concerning a single fetoplacental unit in politocus species such as the rabbit is useful for interspecies comparisons. The results obtained in vivo under physiological conditions indicate that in the rabbit the rate of glucose utilization by the placenta is similar to the rate of glucose utilization by the fetoplacental unit. This suggests that fetal glucose utilization is in the same range as the placental glucose utilization because fetal mass represents 80 to $90 \%$ of the total fetoplacental unit mass (Fig. 2; ' Table 1). This study also demonstrates that glucose utilization measured simultaneously in the same animal using two different techniques (radioactive 2-deoxyglucose and Fick principle methodology) gives very similar values. Interspecies comparison indicates that, near the term, the epitheliochorial placenta of the sheep (2) utilizes three to five times more glucose than the hemochorial placenta of man (17), rat (18), and rabbit (Fig. 2).

A 96-h maternal fast beginning on day 25 of gestation does not decrease glucose utilization rates in the placenta and the fetoplacental unit (Fig. 2). The absence of effects of maternal fasting on placental blood flow and glucose utilization by the fetoplacental unit seems to be specific for the rabbit because large decreases in placental blood flow and glucose utilization have been observed in rat and sheep (18-21). Fetal metabolic response to maternal fasting can be analyzed on the basis of the changes occurring in blood substrate and plasma hormone concentrations in mothers and fetuses (Table 2). The significant decrease in maternal blood glucose was not reflected to the same extent in the fetus, suggesting two hypotheses: 1 ) an increased placental transport capacity to maintain adequate glucose transfer from maternal to fetal circulation; and/or 2) a rapid adaptation of fetal metabolism (increased liver glycogenolysis and gluconeogenesis) to compensate for a decrease in placental transfer of glucose. The present data do not permit determination of which mechanism is operative, but a premature appearance of fetal liver gluconeogenesis has been shown to occur during maternal fasting in the rabbit $(22,23)$. The fall in fetal plasma insulin observed during maternal fasting could be explained by the fact that the fetal pancreas is sensitive to small changes of fetal glucose concentration as demonstrated in vitro (24) and in vivo (25) in the rat and in the sheep $(26,27)$. The decrease in fetal plasma insulin during fasting could be subsequently responsible for the premature induction of fetal liver phosphoenolpyruvate carboxykinase, the rate limiting enzyme of gluconeogenesis $(22,23)$, and thereby preserve fetal glucose homeostasis.

Another point to stress is the selective transfer of fat-derived substrates across the rabbit placenta. Despite very high $\mathrm{KB}$ concentration in maternal plasma, $\mathrm{KB}$ were not transported to a large extent from maternal to fetal circulation during 
maternal fasting (Table 2; Fig. 2). Thus, in the rabbit, as in the sheep (28), KB cannot serve as alternative fuels for fetal tissues. This is in contrast to what occurs in the rat where a large amount of $\mathrm{KB}$ is transferred to the fetus during maternal fasting (29-31). By contrast, a significant transplacental transfer of FFA occurs during maternal fasting in the rabbit as evidenced by the 3-fold increase in fetal plasma (Table 2; Fig. 1). Whether or not FFA was used as an energy source in the fetal rabbit was not determined herein but it has been shown that FFA can be stored as triglycerides in liver and adipose tissue $(8,32,33)$.

Use of the glucose analog, 2DG, permits measurement of glucose utilization by individual fetal tissues in animal species where small size does not allow vascular catheterization in the fetus. In addition, this technique may help to determine whether specific modifications occur in individual fetal tissues during maternal fasting, which may be masked when estimating the overall glucose utilization rate by the fetoplacental unit. In vivo, in the fed state, glucose utilization indices are similar in most fetal tissues studied (hindlimb muscles, diaphragm, white and brown adipose tissue, skin, and brain), i.e. about $25 \mathrm{nmol} / \mathrm{min} /$ $\mathrm{g}$ tissue, but differ in the heart $(55 \mathrm{nmol} / \mathrm{min} / \mathrm{g})$ and the liver $(11 \mathrm{nmol} / \mathrm{min} / \mathrm{g})$. In utero the heart exhibits the highest rate of glucose utilization among fetal tissues similar to the ventricle in the adult rat (34) and rabbit (35). It is noteworthy that in the fetal rabbit, basal and fasted glucose metabolic indices are 5 to 10 times lower than those measured in the fetal rat (10). These data further emphasize the species specificity previously pointed out for placental blood flow and glucose utilization rate. The maintenance of a constant glucose utilization index in most fetal tissues after $96 \mathrm{~h}$ of maternal fasting is probably due to the fact that fetal blood glucose concentration was not significantly decreased. In addition, these results suggest that most fetal tissues are not affected by hypoinsulinemia when blood glucose concentration remains constant. This is in contrast to data obtained in vivo in the fetal lamb (36) where fetal glucose uptake is correlated with arterial plasma insulin levels and in the fetal rat (10) where the rate of glucose utilization in several fetal tissues is increased by exogenous insulin. During maternal fasting in the rabbit, brown adipose tissue and liver are the only fetal tissues in which glucose utilization indices are significantly decreased. Both tissues possess insulin receptors that can be phosphorylated as early as day 20 of gestation (37). Thus the decreased glucose utilization observed in these tissues in the presence of fetal hypoinsulinemia in the fetuses of fasted mothers could be interpreted as a sign of a higher insulin sensitivity in comparison to other fetal tissues.

In conclusion, this study has demonstrated that the rabbit fetus maintains a physiological blood glucose level and normal rates of glucose utilization in most tissues after a 96-h maternal fast during late gestation. This suggests that selective and specific adaptations may be set up within the fetoplacental unit to protect the fetus and the placenta from the adverse effects of maternal undernutrition.

Acknowledgments. The authors are indebted to R. and J. P. Urbe and G. Orain for taking care of the animals and $M$. Fernandez for the preparation of the manuscript.

\section{REFERENCES}

1. Comline RS, Silver M 1976 Some aspects of foetal and uteroplacental metab olism in cows with indwelling umbilical and uterine vascular catheters. J Physiol (Lond) 111:1823-1832

2. Meschia G, Battaglia FC, Hay WW, Sparks JW 1980 Utilization of substrates by the ovine placenta in vivo. Fed Proc 39:245-249

3. Block SM, Sparks JW, Johnson RL, Battaglia FC 1985 Metabolic quotients of the gravid uterus of the chronically catheterized guinea-pig. Pediatr Res 19:840-845

4. Gilbert M, Hauguel S, Bouisset M 1984 Uterine blood flow and substrate uptake in conscious rabbit during late gestation. Am J Physiol 247:E574E580
5. Battaglia FC, Meschia G 1978 Principal substrates of fetal metabolism. Physiol Rev 58:499-527

6. Ferré P, Leturque A, Burnol AF, Pénicaud L, Girard J 1985 A method to quantify glucose utilization in vivo in skeletal muscle and white adipose tissue of the anesthetized rat. Biochem J 228:103-110

7. Elphick MC, Hudson DG, Hull D 1975 Transfer of fatty acids across the rabbit placenta. J Physiol (Lond) 252:29-42

8. Edson JL, Hudson DG, Hull D 1975 Evidence for increased fatty acid transfer across the placenta during a maternal fast in rabbits. Biol Neonate 27:50-55

9. Leturque A, Ferré P, Burnol AF, Kandé J, Maulard P, Girard J 1986 Glucose utilization rate and insulin sensitivity in vivo in tissues of virgin and pregnant rats. Diabetes 35:172-177

10. Leturque A, Revelli JP, Hauguel S, Kandé J, Girard J 1987 Hyperglycemia and hyperinsulinemia increase glucose utilization in fetal rat tissues. Am J Physiol 253:E616-E620

11. Girard JR, Ferré P, Gilbert M, Kervran A, Assan R, Marliss EB 1977 Fetal metabolic response to maternal fasting in the rat. Am J Physiol 232:E456$\mathrm{E} 463$

12. Villee CA 1953 The metabolism of human placenta in vitro. $\mathrm{J}$ Biol Chem 205:112-123

13. Dawkins MJR 1961 Changes in glucose-6-phosphatase activity in liver and kidney at birth. Nature 191:72-73

14. Williamson DH, Mellamby $\mathbf{J}$, Krebs MA Enzymatic determination of $B$ hydroxybutyrate and acetoacetate in blood. Biochem J 82:90-96

15. Hohorst $\mathrm{HJ} 1965 \mathrm{~L}(+)$ Lactate determination with lactic dehydrogenase and DNP. In: Bergmeyer HU (ed) Methods of Enzymatic Analysis. Academic Press, New York, pp 266-270

16. Hauguel S, Gilbert M, Girard J 1987 Pregnancy induced insulin resistance in liver and skeletal muscles of the conscious rabbit. Am J Physiol 252:E165E169

17. Hauguel S, Desmaizières V, Challier JC 1986 Placental glucose uptake, transfer and utilization as functions of maternal glucose concentration. Pediatr Res 20:269-273

18. Leturque A, Hauguel S, Kandé J, Girard J 1987 Glucose utilization by the placenta of anaesthetized rats: effects of insulin, glucose and ketone bodies. Pediatr Res 22:483-487

19. Hay WW, Sparks JW, Wilkening AB, Battaglia FC, Meschia G 1984 Fetal glucose uptake and utilization as functions of maternal glucose concentration. Am J Physiol 246:E237-E242

20. Morriss FH, Rosenfeld CR, Crandell SS, Adcock EW 1980 Effects of fasting on uterine blood flow and substrate uptake in sheep. J Nutr 110:2433-2443

21. Gilbert M, Leturque A 1982 Fetal weight and its relationship to placental blood flow and placental weight in experimental intrauterine growth retardation in the rat. J Dev Physiol 4:237-246

22. Jones CT, Michael E, Lafeber HN, Band GC 1984 Models for nutritional research on the fetus: problems and pitfalls. Proc Nutr Soc 43:179-188

23. Girard J 1987 Gluconeogenesis in late fetal and early neonatal life. Biol Neonate 50:237-258

24. Milner RDG, Leach FN, Ashworth MA, Cser A, Jack PMB 1975 Development of pathways of insulin secretion in the rabbit. J Endocrinol 64:349-361

25. Kervran A, Girard JR 1974 Glucose-induced increase of plasma insulin in the rat fetus in utero. J Endocrinol 62:545-551

26. Basset JM, Madill D 1974 The influence of maternal nutrition on plasma hormone and metabolite concentrations of fetal lambs. J Endocrinol 61:465477

27. Philips AF, Carson BA, Meschia G, Battaglia FC 1978 Insulin secretion in fetal and newborn sheep. Am J Physiol 235:E467-E474

28. Pethick DW, Lindsay DB, Barker PJ, Northrop AJ 1983 The metabolism of circulating non-esterified fatty acids by the whole animal, hindlimb muscle and uterus of pregnant ewes. Br J Nutr 49:129-143

29. Hummel L, Schinckmann R, Zimmermann T 1983 Maternal-fetal transfer of free fatty acids during late gestation in the rat. Biomed Biochem Acta 42:143145

30. Shambaugh GE, Mrozack SC, Freinkel N 1977 Fetal fuels I: utilization of ketones by isolated tissues at various stages of maturation and maternal nutrition during late gestation. Metabolism 26:623-635

31. Shambaugh GE, Koehler RA, Freinkel N 1977 Fetal fuels II: Contributions of selected carbon fuels to oxidative metabolism in rat conceptus. Am J Physio 233:E457-E461

32. Girard J, Duée PH, Pégorier JP, Escriva F, Decaux JF 1985 Fatty acid oxidation and ketogenesis during development. Reprod Nutr Dev 25:303-319

33. Elphick MC, Edson JL, Lawlor JP, Hull D 1978 Source of fetal stored lipids during maternal starvation in rabbits. Biol Neonate 34:146-149

34. Issad T, Pénicaud L, Ferré P, Kandé J, Baudon MA, Girard J 1987 Effects of fasting on tissue glucose utilization in conscious resting rats: major glucose sparing effect in working muscles. Biochem J 246:241-244

35. Hauguel S, Leturque A, Gilbert M, Girard J 1987 Effects of pregnancy and fasting on muscle glucose utilization in the rabbit. Am J Obstet Gynecol (in press)

36. Hay WW, Meznarich HK, Sparks JW, Battaglia FC, Meschia G 1985 Effect of insulin on glucose uptake in near-term fetal lambs. Proc Soc Exp Biol Med 178:557-564

37. Peyron JF, Samson M, Van Obbergen E, Brandenburg D, Fehlman M 1985 Appearance of a functional insulin receptor during rabbit embryogenesis. Diabetologia 28:369-372 